\title{
Candida arthritis: cellular immune responses of synovial fluid and peripheral blood lymphocytes to Candida albicans
}

Department of Internal Medicine,

Johannes Gutenberg

University of Mainz,

Germany

E Hermann

W-J Mayet

O Klein

A W Lohse

C Trautwein

T Poralla

K-H Meyer

zum Büschenfelde

Department of

Orthopedics,

Johannes Gutenberg

University of Mainz,

Germany

I Michiels

Correspondence to:

Professor K-H Meyer

zum Büschenfelde,

I Department of Internal

Medicine,

Johannes Gutenberg

University of Mainz,
Langenbeckstr 1,

6500 Mainz, Germany.

Accepted for publication 28 August 1990

Elisabeth Hermann, Werner-J Mayet, Ortwin Klein, Ansgar W Lohse, Christian Trautwein, Ivo Michiels, Thomas Poralla, Karl-H Meyer zum Büschenfelde

\begin{abstract}
A case of septic Candida albicans arthritis of the knee in a patient with systemic candidiasis is presented. Systemic and intra-articular cellular immune responses to $C$ albicans and various bacterial antigens were monitored for 15 weeks. It is shown that the candida induced blastogenesis of synovial fluid lymphocytes was much more stimulated than that of peripheral blood lymphocytes, and that the proportion of activated cells expressing HLA class II antigens was markedly. increased in the synovial fluid. Strong cellular immune responses to Candida albicans could still be shown many weeks after the synovial fluid aspirates had become sterile. For the first time synovial fluid derived, CD4 positive $T$ lymphocyte clones with specificity for candida antigens were characterised and further propagated in vitro.
\end{abstract}

Systemic candidiasis is an increasing problem in immunocompromised subjects and in patients in hospital. Candida infections of bone and joints are, nonetheless, exceedingly rare. Among different host related and iatrogenic factors underlying malignant disease, ${ }^{1}$ heroin abuse, ${ }^{2}$ corticosteroid or immunosuppressive treatment, ${ }^{3}$ surgical procedures, ${ }^{45}$ intravenous hyperalimentation, ${ }^{67}$ and prolonged antibiotic treatment ${ }^{4}$ may contribute to the pathogenesis of candida septicaemia and arthritis. In patients without candidaemia, isolated joint infection can be caused by contamination of the joint during the intra-articular administration of steroids. ${ }^{8}$

The ability of Candida albicans preparations to induce lymphocyte blastogenesis in vitro is well known, ${ }^{9}$ and lymphocyte proliferation assays in response to candida are currently used to monitor $\mathbf{T}$ cell dependent immune responses in various disease states. ${ }^{10}$ Little attention has been paid, however, to published reports of the cellular immunological aspects of candida arthritis. In this report we describe the distribution of synovial fluid lymphocyte subsets, $T$ cell activation events, and the $T$ cell response to fungal antigens in a patient with candida arthritis after operation for a brain tumour and systemic corticosteroid and antibiotic treatment.

\section{Case report}

A 62 year old man was admitted to the department of neurosurgery of the University Hospital of Mainz, on 5 April 1989 for surgical removal of a neurinoma of the right tenth cranial nerve. Preoperative evaluation showed him to be in good general health. His past history was unremarkable apart from a medial meniscectomy of the right knee five years previously. The operation was undertaken on 8 April and systemic dexamethasone was applied during the first postoperative days. Postoperative paresis of the right cranial nerves IX, X, and XII required parenteral nutrition for a considerable time before a percutaneous endoscopic gastrostomy could be placed on 10 May. In early May he developed Pseudomonas aeruginosa pneumonia, which was treated with systemic antibiotics.

In late May 1989 he complained of swelling and aching pain in the right knee. Examination showed a markedly swollen and warm knee with an effusion; no other joints were affected. An aspirate from the right knee yielded $80 \mathrm{ml}$ of turbid light yellow synovial fluid. The white cell count was $15 \times 10^{9} / 1$. Gram stain of the fluid was negative, but a culture grew $C$ albicans. At this time the patient's central venous catheter was removed. The catheter tip was cultured and was also shown to be contaminated with $C$ albicans. Furthermore, candida was cultured from sputum and urine and serological tests for candida antibodies were highly positive (haemagglutination test $1 / 640$, positive tests for IgA and IgG antibodies to candida in an enzyme linked immunosorbent assay (ELISA) system). Parenteral amphotericin B treatment $(0 \cdot 1 \mathrm{mg} / \mathrm{kg}$ daily) was started in combination with flucytosine $(150 \mathrm{mg} / \mathrm{kg}$ daily) on 1 June, and the amphotericin B dosage was increased stepwise up to $0.5 \mathrm{mg} / \mathrm{kg}$ daily. Synovial fluid aspirates became sterile after two weeks of treatment. As the right knee remained tender and swollen, nonetheless, synovectomy had to be performed on 23 June-that is, three weeks after the onset of fungostatic treatment. Histological examination of the synovial tissue showed a chronic granulomatous synovitis with villous hypertrophy, ulcerations of the lining cell layer, and with dense lymphoplasmacellular and sometimes neutrophil infiltrations (fig 1). Staining for fungi was negative and candida organisms could not be identified. In July the patient developed dense infiltrates of the left lung, fever, and acute respiratory failure that required treatment on a respirator for six weeks. Fibrebronchoscopic lavage and biopsies showed candida pneumonia of the left lung. During this period the patient had other infectious complications, such as pneumonia and urinary tract infections caused by different Enterobacteriaceae (Pseudomonas aeruginosa, Escherichia coli). Arthrocentesis of the right knee was repeated on 

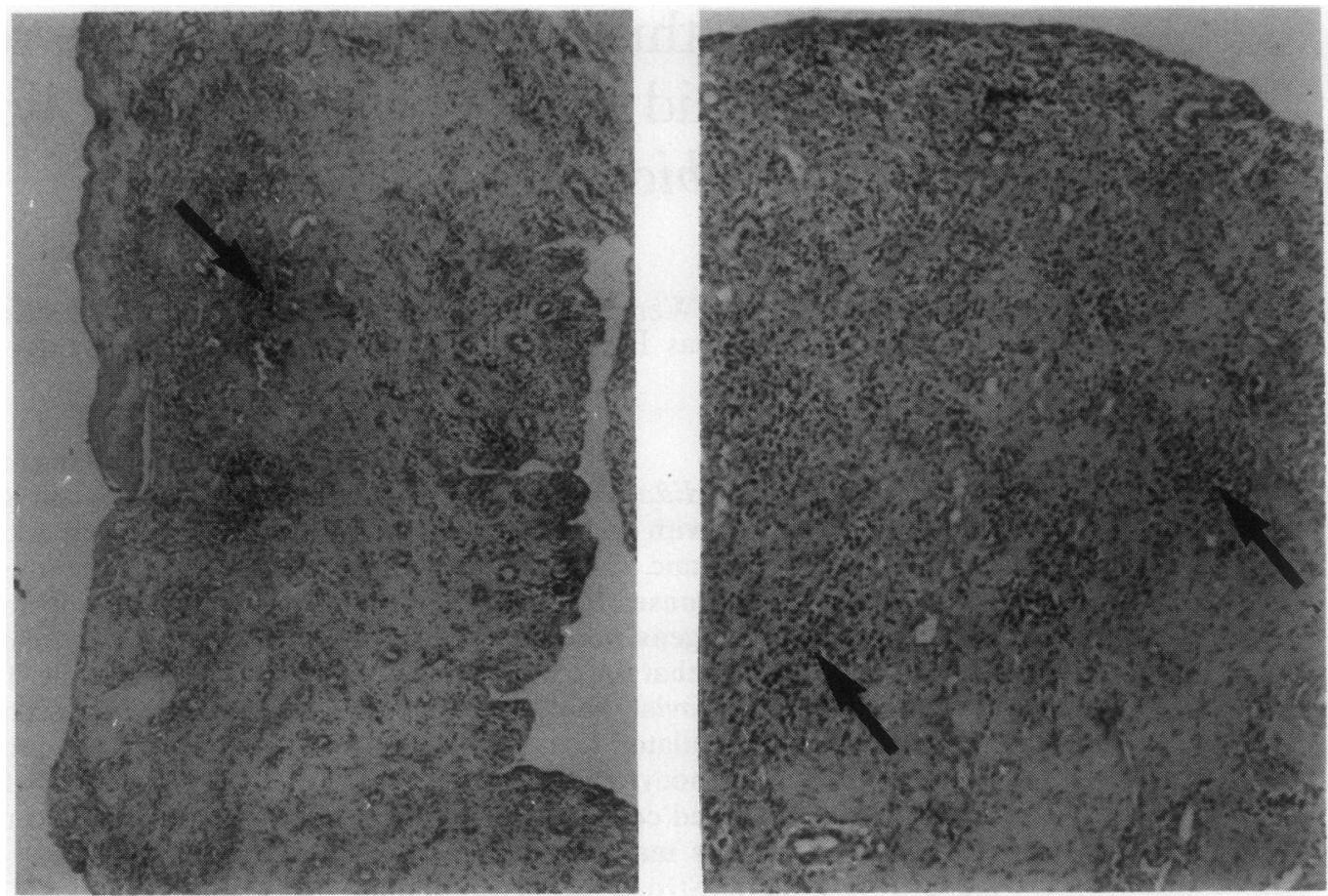

Figure 1 Photomicrographs of synovial tissue of the right knee, obtained by synovectomy, showing chronic granulomatous synovitis with a villous hypertrophy, ulcerations of the lining cell layer, and with dense lymphoplasmacellular (arrows) and, sometimes, neutrophil infiltrations.

7 July and on 1 September because of small effusions $(20 \mathrm{ml})$. The synovial fluid cultures were both sterile. Amphotericin B and flucytosine treatment was continued until the end of October 1989; bone marrow and renal function was closely followed by estimation of red and white blood cell and thrombocyte counts, blood urea nitrogen, and creatinine concentrations. At the time of discharge in November 1989 the patient was able to walk again. The right knee and the lung have been asymptomatic since then.

\section{Materials and methods}

PREPARATION OF MONONUCLEAR CELLS

Synovial fluid and peripheral blood of the patient were collected into sterile heparinised tubes at a time when synovial fluid cultures had already become negative for $C$ albicans. Synovial fluid was diluted 1:4 and blood 1:2 in RPMI 1640 (Gibco Laboratories, Karlsruhe, Germany) supplemented with $100 \mathrm{U}$ of penicillin, $100 \mu \mathrm{g}$ of both streptomycin and amphotericin B per ml. Mononuclear cells were prepared by FicollHypaque density gradient centrifugation, washed, and cryopreserved exactly as described. ${ }^{11}$ Monocyte and B cell enriched peripheral blood mononuclear cells $\left(\mathbf{E}^{-}\right)$were obtained by removing $T$ cells after rosetting with neuraminidase treated sheep erythrocytes. In some experiments peripheral blood mononuclear cells from umbilical cord blood were used as responders. Peripheral blood and synovial fluid mononuclear cells were analysed for their reactivity with monoclonal antibodies by indirect immunofluorescence on an EPICS C cell sorter (Coulter Electronics, Krefeld, Germany).

\section{MICROBIAL ANTIGENS}

C albicans, Salmonella typhimurium, Escherichia coli, Pseudomonas aeruginosa, Campylobacter jejuni, and Yersinia enterocolitica $\mathrm{O} 3$ were grown as described. ${ }^{11} 12$ The micro-organisms were harvested after 48 hours, washed and resuspended in phosphate buffered saline, and sterilised by autoclaving. The supernatants were diluted in phosphate buffered saline to a protein concentration of $10 \mathrm{mg} / \mathrm{ml}$. Aliquots of $1 \mathrm{ml}$ were stored at $-20^{\circ} \mathrm{C}$. In the initial evaluation of the antigens different antigen dilutions in assay medium (RPMI 1640 supplemented with $10 \%$ human $\mathrm{AB}$ serum) were tested in peripheral blood and synovial fluid lymphocyte proliferation assays in patients with postinfectious arthritis. ${ }^{11}$ The optimal proliferation response was obtained with final antigen concentrations of between 10 and $100 \mu \mathrm{g}$ protein $/ \mathrm{ml}$. The Enders strain of mumps virus was grown in embryonated chicken egg allantoic fluid and stored at $-80^{\circ} \mathrm{C}$.

\section{MONOCLONAL ANTIBODIES}

Monoclonal antibodies against monomorphic determinants on HLA class II molecules DP,

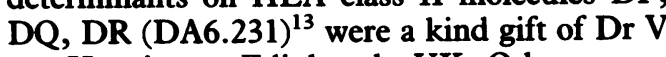
van Heyningen, Edinburgh, UK. Other monoclonal antibodies (anti-CD4, CD8, CD3, CDw14 (Mo2), NKH-1) were purchased from Coulter Electronics (Krefeld, FRG).

[ ${ }^{3}$ H]THYMIDINE UPTAKE PROLIFERATION ASSAY FOR SYNOVIAL AND BLOOD MONONUCLEAR CELLS Lymphocyte proliferation assays were performed as described previously ${ }^{11}$ with $5 \times 10^{4}$ cells per well of 96-well microtitre plates (Nunc, 
Roskilde, Denmark) in a total volume of $100 \mu$ of assay medium in triplicate cultures. The appropriate antigen was diluted to a final concentration of $50 \mu \mathrm{g}$ protein $/ \mathrm{ml}$. On day 5 of culture $\left[{ }^{3} \mathrm{H}\right]$ thymidine (Amersham International, Amersham, UK) at $9 \mathrm{kBq} /$ well was added. Proliferative responses were then determined by 24 hours $\left[{ }^{3} \mathrm{H}\right]$ thymidine incorporation.

GENERATION AND CLONING OF A SYNOVIAL FLUID DERIVED, CANDIDA REACTIVE T CELL LINE

Synovial fluid mononuclear cells were seeded into 12-well plates (Costar, Cambridge, USA) at $1 \times 10^{6}$ cells per well in $1.5 \mathrm{ml}$ RPMI 1640 supplemented with $10 \%$ human $A B$ serum and candida antigen at a final protein concentration of $50 \mu \mathrm{g} / \mathrm{ml}$. Cultures were incubated at $37^{\circ} \mathrm{C}$ in a humidified atmosphere of $5 \% \mathrm{CO}_{2}$. After four days of culture $0.5 \mathrm{ml}$ of culture medium supplemented with $20 \mathrm{U} / \mathrm{ml}$ recombinant interleukin 2 (Boehringer Mannheim, Germany) was added to each well. Culture medium supplemented with candida antigen and recombinant interleukin 2 was replaced on day 8 . On days 12 and 22 the cultures were split with new supplemented culture medium and with $1.5 \times 10^{6}$ irradiated (40 Gy) autologous peripheral blood lymphocytes per well. Subsequent splits were made about every four to six days with recombinant interleukin 2 supplemented medium. After 30 days of culture this $T$ cell line was cloned in Terasaki microtest plates (Nunc, Roskilde, Denmark) by limiting dilution using candida $(50 \mu \mathrm{g} / \mathrm{ml})$ and recombinant interleukin $2(20 \mathrm{U} / \mathrm{ml})$ supplemented culture medium and autologous irradiated (40 Gy) peripheral blood mononuclear feeder cells $\left(1 \cdot 2 \times 10^{4}\right.$ cells/well $)$. The plates were cultured at $37^{\circ} \mathrm{C}$ in a humidified atmosphere of $5 \% \mathrm{CO}_{2}$ and were checked for growing colonies on days 8, 10, and 12 . Growing $\mathrm{T}$ lymphocyte clones were transferred to larger plates (96-well microtitre plates and 12-well plates (Costar, Cambridge, USA)) with recombinant interleukin 2 supplemented culture medium and were then tested for reactivity to candida and two control antigens in a proliferation assay after another week of culture. Clones of interest were further expanded in medium supplemented with recombinant interleukin 2 in six-well plates (Falcon, Becton Dickinson, New Jersey, USA) and restimulated by oxidised feeder cells in the absence of a mitogen as described. ${ }^{14}$

Table 1 Phenotypic analysis by fluorescence activated cell sorting of peripheral blood and synovial fluid mononuclear cells obtained on 14 fune (three weeks after the onset of arthritis) and $7 \mathcal{F}$ uly 1989 (six weeks after the onset of arthritis). Results are given as the percentage of mononuclear cell subsets in peripheral blood and synovial fluid

\begin{tabular}{|c|c|c|c|c|}
\hline \multirow{2}{*}{$\begin{array}{l}\text { Monoclonal } \\
\text { antibody }\end{array}$} & \multicolumn{2}{|l|}{14 fune 1989} & \multicolumn{2}{|l|}{7 fuly 1989} \\
\hline & Peripheral blood & Synovial fluid & Peripheral blood & Synovial fluid \\
\hline $\begin{array}{l}\text { CD3 } \\
\text { CD4 } \\
\text { CD8 } \\
\text { Mo2* } \\
\text { NKH-1 } \\
\text { DA6.231* }\end{array}$ & $\begin{array}{r}60 \cdot 8 \\
66 \cdot 8 \\
15 \cdot 5 \\
2 \cdot 2 \\
15 \cdot 4 \\
19 \cdot 4\end{array}$ & $\begin{array}{r}69 \cdot 0 \\
64 \cdot 7 \\
8 \cdot 1 \\
7 \cdot 4 \\
3 \cdot 0 \\
50 \cdot 0\end{array}$ & $\begin{array}{r}67 \cdot 1 \\
45 \cdot 8 \\
20 \cdot 3 \\
9 \cdot 9 \\
12 \cdot 8 \\
27 \cdot 8\end{array}$ & $\begin{array}{r}70 \cdot 5 \\
61 \cdot 4 \\
8 \cdot 3 \\
10 \cdot 2 \\
4.5 \\
56.8\end{array}$ \\
\hline
\end{tabular}

${ }^{*}$ Mo2=anti-CDw14; DA6.231 = anti-HLA class II antigens.
T CELL PROLIFERATION ASSAY FOR T CELL CLONES Proliferative responses were determined in triplicates of $150 \mu \mathrm{l}$ culture medium containing $1 \times 10^{4}$ cloned $T$ cells as responders and $1 \times 10^{4}$ autologous $\mathrm{E}^{-}$as antigen presenting cells in $\mathrm{U}$ shaped, 96-well microtitre plates. Antigens ( $C$ albicans, $Y$ enterocolitica $O 3, S$ typhimurium) were diluted to a final protein concentration of $50 \mu \mathrm{g} / \mathrm{ml}$. Cells were cultured for 48 hours and pulsed with $9 \mathrm{kBq}\left[{ }^{3} \mathrm{H}\right]$ thymidine for the last 24 hours. The proliferative responses were expressed as mean counts/min incorporation of triplicates.

\section{Results}

QUANTITATIVE ANALYSIS OF MONOCLONAL ANTIBODY DEFINED LYMPHOCYTE SUBSETS

Table 1 shows the phenotypic analysis of peripheral blood and synovial fluid mononuclear cells obtained on 14 June and 7 July 1989. A decreased number of CD8 + T cells and of natural killer (NK) cells were found in the synovial fluid in comparison with peripheral blood. Activated T cells, as defined by the expression of HLA class II antigens, were significantly increased in the synovial fluid.

PROLIFERATIVE RESPONSES OF PERIPHERAL BLOOD AND SYNOVIAL FLUID MONONUCLEAR CELLS TO Candida albicans

The sensitivity of lymphocytes from peripheral blood and synovial fluid to $C$ albicans and to various bacterial antigens was investigated over a period of 15 weeks from the onset of arthritis up to the time when therapeutic arthrocentesis was necessary for the last time. Figure 2 shows the results of the lymphocyte proliferation assays. All proliferative responses were measured over six days as previous kinetic studies had shown that the peak response to bacterial and candida antigens occurred at this time. It could be shown that in the first weeks of candida arthritis the proliferative response of synovial fluid mononuclear cells was specific for candida antigens, whereas during the course of the disease and of following various enterobacterial superinfections of the urinary and respiratory tract during long term respirator treatment synovial fluid as well as peripheral blood mononuclear cell proliferative responses to enterobacterial antigens became evident. The candida reactive lymphocyte proliferation could be completely blocked by monoclonal antibodies to HLA class II antigens. $C$ albicans antigens were not able to induce a lymphoproliferation of umbilical cord blood cells (data not shown), thus excluding a possible non-specific mitogenic effect of the preparations.

GROWTH AND ANTIGEN SPECIFICITY OF SYNOVIAL FLUID DERIVED T CELL CLONES

In the cloning experiment with the candida reactive, synovial fluid derived $\mathrm{T}$ cell line, $35 \mathrm{~T}$ lymphocyte clones out of 600 seeded wells were grown (cloning efficiency of $5 \cdot 8 \%$ ) and further propagated up to a cell count of $2-3 \times 10^{6}$ cells per clone. The clones were then tested for their 
24.5.89

21.6.89

7.7.89

1.9 .89

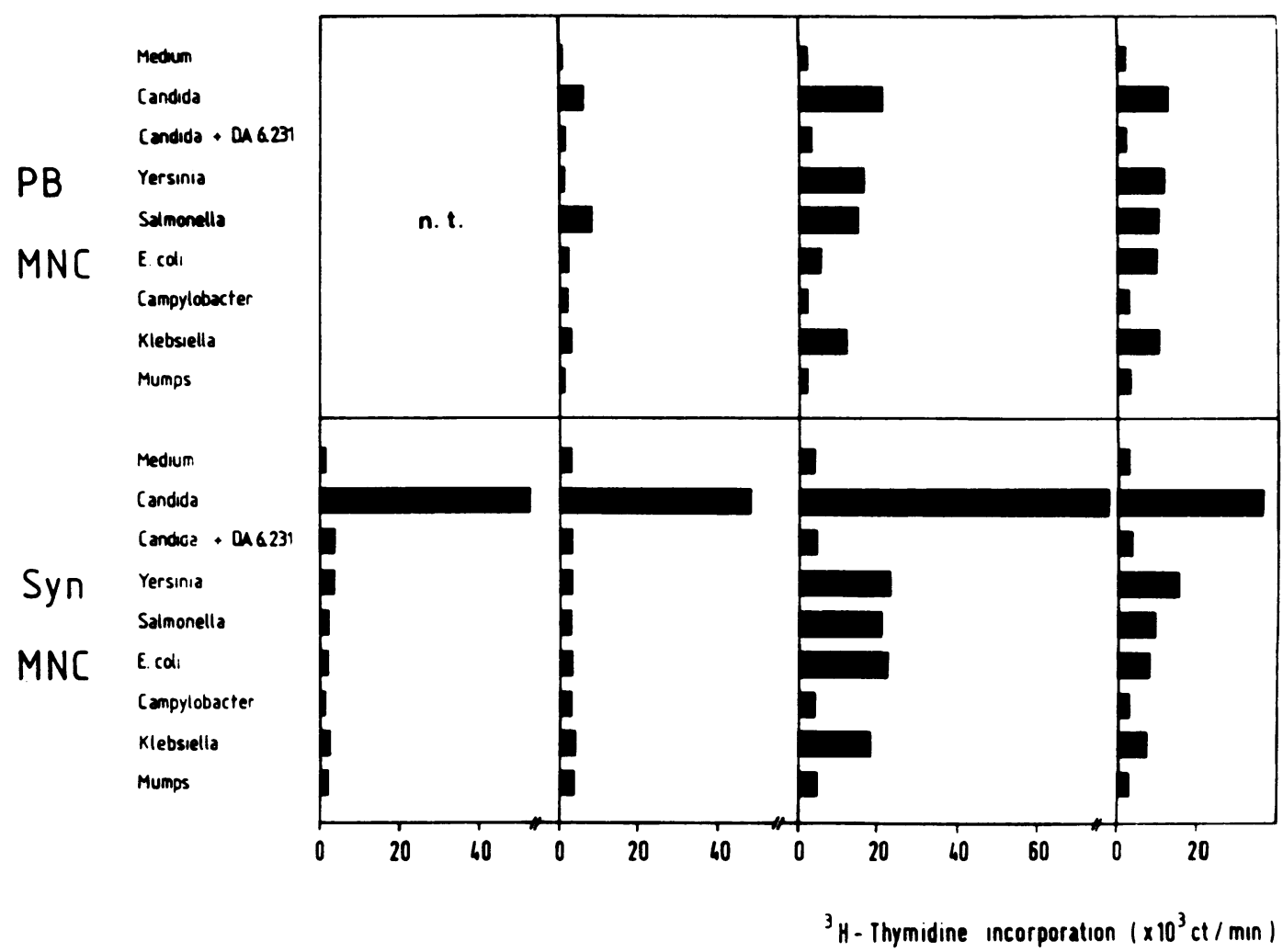

Figure 2 Proliferative responses of peripheral blood (PB) and synovial fluid (Syn) mononuclear cells $(M N C)$ taken on different days during the course of candida arthritis. The stimuli consisted of culture medium alone, heat killed Candida albicans, Yersinia enterocolitica O9, Salmonella typhimurium, Escherichia coli, Campylobacter jejuni, Klebsiella pneumoniae, and of mumps virus. The proliferative response to candida was inhibited by a monoclonal antibody to a common determinant on $H L A-D R, D P, D Q(D A 6.231)$.

proliferative responses to $C$ albicans, $Y$ enterocolitica, and $S$ typhimurium. Nine out of the $35 \mathrm{~T}$ lymphocyte clones showed a marked and specific proliferative response to $C$ albicans with a stimulation index between 9.9 and 103 when compared with the medium control (table 2). The $C$ albicans reactive $\mathrm{T}$ lymphocyte clones were of the CD4+/CD8 - phenotype. As shown in table 2 the monoclonal antibodies specific for HLA class II antigens-DA6.231-inhibited candida induced proliferation strongly. These results suggest that the proliferation of $T$ lymphocyte clones to $C$ albicans represents an HLA class II restricted T cell response.

Table 2 Proliferative responses of Candida albicans reactive, synovial fluid derived $T$ cell clones to heat inactivated antigens of Candida albicans, Yersinia enterocolitica $\mathrm{O}^{3}$, and Salmonella typhimurium. Results are expressed as mean counts per minute $\left[{ }^{3} \mathrm{H}\right]$ thymidine incorporation

\begin{tabular}{|c|c|c|c|c|c|c|}
\hline \multirow{2}{*}{$\begin{array}{l}\text { Clone } \\
\text { No }\end{array}$} & \multirow{2}{*}{$\begin{array}{l}\text { Medium } \\
\text { control }\end{array}$} & \multicolumn{5}{|l|}{$E^{-}$} \\
\hline & & Medium & Candida & $\begin{array}{l}\text { Candida } \\
+ \\
\text { DA6.23I }\end{array}$ & $\begin{array}{l}\text { Yersinia } \\
\text { enterocolitica }\end{array}$ & Salmonella \\
\hline $\begin{array}{l}\mathrm{KH}-1 \\
\mathrm{KH}-3 \\
\mathrm{KH}-12 \\
\mathbf{K H}-14 \\
\mathbf{K H}-19 \\
\mathbf{K H}-24 \\
\mathbf{K H}-25 \\
\mathbf{K H}-31 \\
\mathbf{K H}-35\end{array}$ & $\begin{array}{r}983 \\
284 \\
545 \\
982 \\
377 \\
2200 \\
1737 \\
1075 \\
470\end{array}$ & $\begin{array}{r}1368 \\
1040 \\
509 \\
893 \\
1599 \\
1016 \\
1386 \\
1814 \\
1198\end{array}$ & $\begin{array}{ll}38 & 085 \\
29 & 355 \\
31 & 510 \\
25 & 842 \\
10 & 006 \\
45 & 113 \\
17 & 239 \\
21 & 495 \\
15 & 283\end{array}$ & $\begin{array}{r}532 \\
876 \\
1323 \\
2297 \\
579 \\
963 \\
2031 \\
1075 \\
784\end{array}$ & $\begin{array}{r}938 \\
2428 \\
434 \\
2934 \\
1429 \\
797 \\
728 \\
1393 \\
1253\end{array}$ & $\begin{array}{r}1159 \\
1411 \\
473 \\
2565 \\
2365 \\
1522 \\
784 \\
1023 \\
860\end{array}$ \\
\hline
\end{tabular}

$\mathrm{T}$ cell clones $\left(10^{4} /\right.$ well) were stimulated with different antigens in the presence of autologous $\mathrm{T}$ cell depleted peripheral blood mononuclear cells $\left(\mathrm{E}^{-}, 10^{4} / \mathrm{well}\right)$ as antigen presenting cells. The proliferative response to Candida albicans was inhibited by monoclonal antibodies to a common proliferative response to Candida albicans was inhi
determinant on HLA-DR, DP, DQ (DA6.231).

\section{Discussion}

In our patient candidaemia, candida arthritis, and candida pneumonia developed in association with an underlying disease (pneumonia), previous surgical procedures, the use of central venous catheters with prolonged parenteral hyperalimentation, and steroid and multiple antibiotic treatment. The persistence of proliferative and granulomatous knee synovitis and the development of severe candida pneumonia required surgical synovectomy of the affected knee as well as prolonged parenteral antimycotic treatment with amphotericin B and flucytosine. Although the clinical experience with candida arthritis is limited, combined surgical, ${ }^{3}$ intravenous, and, sometimes, intra-articular antimycotic treatment ${ }^{1}$ has been reported to be successful in treating the arthritis and systemic candidiasis. In this paper we report for the first time the monitoring of systemic and intraarticular cellular immune responses to $C$ albicans and the propagation of candida reactive, synovial fluid derived $\mathrm{T}$ lymphocyte clones.

Candida elicits strong delayed-type hypersensitivity responses in both man and animals, and yet is extremely difficult to eradicate. Purified polysaccharide extract from $C$ albicans is known to be a 'recall' antigen able to induce in vitro a secondary proliferative response of peripheral blood $T$ lymphocytes from donors that have been previously exposed to candida. ${ }^{12} 15$ In man, chronic mucocutaneous candidiasis or systemic candidiasis are generally 
seen in association with defects in the cell mediated immune response. ${ }^{16}$

There is general agreement that mononuclear and neutrophil phagocytes have an important role in resistance to candida infection. ${ }^{17-19}$ Within their phagolysosomes, activated phagocytes can kill the micro-organisms effectively by lysosomal enzymes and reactive oxygen metabolites. ${ }^{20}$ The level of activation of host phagocytes seems to be dependent on an intact cooperation between mononuclear phagocytes and $T$ cells. In an animal model Ashman was able to demonstrate a requirement for $\mathrm{T}$ cells in the host response to primary infection with Candida albicans and showed that responses were regulated by genes of the major histocompatibility complex. ${ }^{21}$

In our patient, who had systemic candidiasis and candida arthritis, the proportion of HLA class II expressing cells was markedly increased in the synovial fluid, suggesting that synovial fluid lymphocytes were activated in vivo at the site of local candida infection. Furthermore, the candida induced blastogenesis of synovial fluid mononuclear cells was much more marked than that of peripheral blood mononuclear cells, suggesting an increased prevalence of candida specific $T$ cells in the joint.

The cloning of $T$ cells derived from the synovial fluid gave us the opportunity to demonstrate the antigen specificity and to characterise the phenotype of candida reactive clones. The candida specific proliferative responses of peripheral blood and synovial fluid $T$ lymphocytes as well as of candida specific $T$ lymphocyte clones could be inhibited by monoclonal antibodies to HLA class II antigens, indicating a classical way of antigen recognition. HLA class II restriction of candida induced, peripheral blood $\mathrm{T}$ cell proliferation has also been shown in a previous study. ${ }^{12}$ Thus our results suggest that helper $\mathrm{T}$ cells of the CD4+ phenotype with specificity for candida are increased in the synovial membrane or synovial fluid of the infected joint. By the secretion of interferon $\gamma$ and interleukins the $T$ cells may then activate macrophages ${ }^{20}$ and induce the effector phase of an effective intracellular killing.

Interestingly, after 14 days of combined systemic treatment with amphotericin B and flucytosine we failed to show candida organisms by synovial fluid cultures or by special stainings for fungal antigens in the samples obtained by synovectomy despite evidence of continuing joint inflammation. These findings are consistent with those of other authors ${ }^{3}$ who failed to show candida in synovial fluid or synovial tissue after antifungal treatment had been started. Nevertheless, strong synovial fluid mononuclear cell immune responses to candida could be seen for several months. The latter might be ex- plained by the intra-articular persistence of immunodominant candida breakdown products able to perpetuate $T$ cell activation, and chronic synovitis as has been postulated for other forms of postinfectious arthritis. ${ }^{11} 22$ The availability of candida specific human $T$ cells clones may give us the opportunity to define further $T$ cell epitopes on $C$ albicans.

This work was supported by the Kurt-Eberhard Bode Stiftung in the Stifterverband für die Deutsche Wissenschaft. We thank Miss S Mayer for her excellent technical assistance. Histological examination of the synovectomy samples was performed by $\mathrm{Dr}$ H-P Dienes, Institut für Pathologie, Johannes GutenbergUniversität, Mainz.

1 Poplack D G, Jacobs S A. Candida arthritis treated with amphotericin B. F Pediatr 1975; 87: 989-90.

2 Dupont B, Drouhet E. Cutaneous, ocular, and osteoarticular candidiasis in heroin addicts: new clinical and therapeutic candidiasis in heroin addicts: new clinical and therapeu
aspects in 38 patients. $\mathcal{F}$ Infect $D$ is $1985 ; 152: 577-91$.

3 Lindström F D, Lindholm T. Candida albicans arthritis treated with flucytosine. Ann Interm Med 1973; 79: 131.

4 Noyes F R, McCabe J D, Fekety F R. Acute candida arthritis. f Bone foint Surg [Am] 1973; 55: 169-76.

5 MacGregor R R, Schimmer B M, Steinberg M E. Results of combined amphotericin B-5-fluorocytosine therapy for prosthetic knee joint infected with candida parapsilosis. f Rheumatol 1979; 6: 451-5.

6 Curry C R, Quie P G. Fungal septicemia in patients receiving parenteral

7 Lertratanakul Y, Glassford G H, Rubinstein H M. Arthritis and osteomyelitis due to Candida albicans. A case report. and osteomyelitis due to Can

8 Katzenstein D. Isolated candida arthritis: report of a case and definition of a distinct clinical syndrome. Arthritis Rheum 1985; 28 : $1421-4$.

9 Piccolella E, Lombardi G, Morelli R. Human lymphocyteactivating properties of a purified polysaccharide from Candida albicans: $B$ and $T$ cell cooperation in the mitogenic responses. I Immunol 1980; 125: 2082-8.

10 Cox R A. Cell mediated immunity. In: Howard D H, ed. Fungi pathogens for humans and animals. Part B. New York: Marcel Dekker, 1983: 61-98.

11 Hermann E, Fleischer B, Mayet W J, Poralla T, Meyer zum Büschenfelde K-H. Response of synovial fluid T cell clones to Yersinia enterocolitica antigens in patients with reactive to Yersinia enterocolitica antigens in patients with

12 Ausiello C M, Spangnoli G C, Boccanera M, et al. Proliferation of human peripheral blood mononuclear cells induced by Candida albicans and its cell wall fractions. $\mathcal{J}$ Med Microbio 1986; 22: 195-202.

13 Van Heyningen V, Guy K, Newman R, Steel C M. Human MHC class II molecules as differentiation markers. Immunogenetics 1982; 16: 459-69.

14 Fleischer B. Non-specific propagation of human antigendependent T lymphocyte clones. $\mathcal{J}$ Immunol Methods 1988 ; 109: 215-9.

15 Lombardi G, Piccolella E, Vismara D, Colizzi V, Asherson G L. Candida albicans polysaccharide extract (MPPS) and PPD stimulate the production of interleukin-1 and lymphocyte proliferation. Clin Exp Immunol 1984; 58: 581-6.

16 Kirkpatrick C H. Host factors in defense against fungal infections. Am $\mathcal{F}$ Med 1984; 2 (suppl 4D): 1-12.

17 Louria D B. Candida infection in experimental animals. In: Bodey G B, Fainstein C, eds. Candidiasis New York: Raven Press, 1985: 29-51

18 Bistoni F, Vecchiarelli A, Cenci E, Puccetti P, Marconi P, Cassone A. Evidence for macrophage-mediated protection against lethal Candida albicans infection. Infect Immun 1986; 51 : $668-74$.

19 Fromthing R A, Shadomy H J. An overview on macrophagefungal interactions. Mycopathologica 1986; 73: 77-93.

20 Kaufmann S H E, Flesch I. Immunologische Aspekte von Pilzinfektionen. Hospitalis 1988; 9: 490-7.

21 Ashman R B. Mouse candidiasis. II. Host responses are Tcell dependent and regulated by genes in the major histocompatibility complex. Immunogenetics 1987; 25: histoco 3 .

22 Gaston J S H, Life P F, Granfors K, et al. Synovial T lymphocyte recognition of organisms that trigger reactive arthritis. Clin Exp Immunol 1989; 76: 348-53. 